\title{
Examining the Dimensions of Enterprise Risk Management Implementation Framework, Its Challenges and Benefits: A Study on Malaysian Public Listed Companies
}

\author{
Fong-Woon Lai
}

\begin{abstract}
This paper presents important dimensions for an effective implementation of enterprise risk management (ERM) framework, namely the structure, governance and process dimensions. This paper also examines the penetration intensity of ERM implementation among the sampled public listed companies in Malaysia. The significant elements for the proposed ERM implementation framework, its implementation challenge and the perceived benefits are also discussed. Based on a theorized effective ERM implementation, 3 constructs and their measurement variables are highlighted for further discussion through factor analysis in relation to the significance of the variables' factor loadings. Discussion on the results of the factors extracted vis-à-vis each dimension of ERM implementation intensity, its challenge and the perceived benefit measures will provide insights to a productive practice of ERM by corporations.
\end{abstract}

Index Terms-Enterprise risk management, governance, implementation dimensions, process, structure.

\section{INTRODUCTION}

This paper highlights the dimensions, areas, and elements of a proposed enterprise risk management (ERM) implementation framework. Based on the framework, this paper empirically examines the penetration level of ERM practices among the public listed companies (PLCs) in Malaysia. This paper asserts a notion that a causal relationship exists between three critical aspects of effective ERM implementation program, namely the implementation challenge, the implementation intensity, and the perceived benefits or impacts. Fig. 1 portrays this theorized causal relationship model. Thus, based on the survey performed on the sampled PLCs of Malaysia, this paper also discusses the results of exploratory factor analysis (EFA) performed on 37 variables measuring the constructs of (i) ERM implementation intensity, (ii) implementation challenge, (iii) perceived ERM benefit measures. The objective of this EFA is to describe variability among observed, correlated variables in terms of a potentially lower number of unobserved (latent) variables called factors under each of the above-mentioned construct as depicted in Fig. 1.

Manuscript received April 19, 2013; revised June 25, 2013.

F. W. Lai is with the Department of Management and Humanities, Universiti Teknologi PETRONAS, 31750 Tronoh, Perak, Malaysia (e-mail: laifongwoon@petronas.com.my).

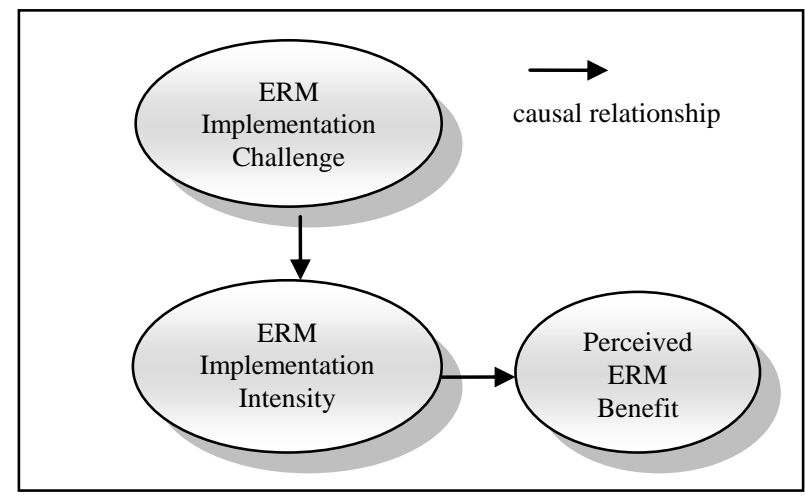

Fig. 1. Constructs in the theorized causal relationship model.

\section{THE PROPOSED ERM IMPLEMENTATION FRAMEWORK}

TABLE I: DIMENSIONS AND AREAS OF ERM IMPLEMENTATION

\begin{tabular}{|c|c|c|c|}
\hline Dimension & Area & & Element / Statement \\
\hline \multirow{4}{*}{ Structure } & \multirow[t]{2}{*}{ ERM Definition } & i1 & $\begin{array}{l}\text { Provides common } \\
\text { understanding of the objectives } \\
\text { of each ERM initiative }\end{array}$ \\
\hline & & i2 & $\begin{array}{l}\text { Provides common terminology } \\
\text { and set of standards of risk } \\
\text { management }\end{array}$ \\
\hline & \multirow{2}{*}{$\begin{array}{l}\text { Performance } \\
\text { measurement }\end{array}$} & i11 & $\begin{array}{l}\text { Identifies key risk indicators } \\
\text { (KRIs) }\end{array}$ \\
\hline & & i12 & $\begin{array}{l}\text { Integrates risk with key } \\
\text { performance indicators (KPIs) }\end{array}$ \\
\hline \multirow{4}{*}{ Governance } & \multirow{2}{*}{$\begin{array}{l}\text { Information and } \\
\text { roles }\end{array}$} & i3 & $\begin{array}{l}\text { provides enterprise-wide } \\
\text { information about risk }\end{array}$ \\
\hline & & i9 & $\begin{array}{l}\text { Enables everyone } \begin{array}{r}\text { to } \\
\text { understand } \\
\text { accountability }\end{array} \\
\text { his/her }\end{array}$ \\
\hline & \multirow[t]{2}{*}{ Compliance } & i5 & $\begin{array}{l}\text { Reduces risk } \\
\text { non-compliance }\end{array}$ \\
\hline & & i6 & $\begin{array}{l}\text { Enables tracking costs of } \\
\text { compliance }\end{array}$ \\
\hline \multirow{6}{*}{ Process } & \multirow{4}{*}{$\begin{array}{l}\text { Integration of } \\
\text { business strategy } \\
\text { and objectives }\end{array}$} & i4 & $\begin{array}{l}\text { Integrates risk with corporate } \\
\text { strategic planning }\end{array}$ \\
\hline & & i8 & $\begin{array}{l}\text { Integrated across all functions } \\
\text { and business units }\end{array}$ \\
\hline & & i10 & $\begin{array}{l}\text { ERM strategy is aligned with } \\
\text { corporate strategy }\end{array}$ \\
\hline & & i13 & $\begin{array}{l}\text { Aligns ERM initiatives to } \\
\text { business objectives }\end{array}$ \\
\hline & $\begin{array}{c}\text { Risk identification } \\
\text { and response }\end{array}$ & i14 & $\begin{array}{l}\text { Provides the rigor to identify } \\
\text { and select risk responses (i.e. } \\
\text { risk- avoidance, reduction, } \\
\text { sharing and acceptance) }\end{array}$ \\
\hline & Risk quantification & i7 & $\begin{array}{l}\text { Quantifies risk to the greatest } \\
\text { extent possible }\end{array}$ \\
\hline
\end{tabular}


The proposed ERM framework is developed to encompass 3 dimensions (i.e. structure, governance and process), which further extends out to 7 areas. These 7 areas are in turn operationalized by 14 implementation elements. For instance, the structure dimension is articulated to be covering two areas, i.e. ERM definition, and performance measurement, and these two areas are operationalized by four implementation elements. Similarly, the governance dimension is to cover two areas (i.e. information and roles, and compliance) with four implementation elements. On the other hand, the process dimension is to include three areas (i.e. integration of business strategy and objectives, risk identification and response, and risk quantification) and with six implementation elements. Table I presents the relevant elements operationalizing the proposed ERM framework which correspond to the relevant areas in the respective dimensions.

\section{THE CONSTRUCTS FOR EFFECTIVE ERM IMPLEMENTATION MODEL}

\section{A. ERM Implementation Intensity}

In relation to the theorized causal relationships for an effective ERM implementation model as depicted in Fig. 1, a data collection instrument through survey questionnaire was developed to collect data for factor analysis. The questionnaire's parameters capture all important elements measuring up the three hypothesized constructs.

For instance, the construct ERM Implementation Intensity is proxied by a measurement metric made up of survey statements (elements) presented to respondents for their assessment. These survey statements come in the form of 5-point Likert's scale covering fourteen statements in the questionnaire corresponding to the fourteen elements of the presented ERM framework as in Table I above, proxying the ERM implementation intensity. The statements gauge the respondents' agreement ratings with regard to the description of various elements found in, or impacts resulted, from the respondent's ERM process implemented. The responses collected from the survey can also be interpreted as a rating for an effective implementation of the firm's ERM program.

The fourteen statements in the questionnaire survey are deemed to be significant for respondents' evaluation. They indicate the defining description of the intensity, maturity, and the penetration level of ERM practices that exist in the surveyed corporations. For instance, in the absence of standard definition for the meanings of the various terms used in ERM initiatives and without the provision of a precious goal for its implementation, it is difficult to envisage a successful implementation of ERM program. Hence, the inclusion of statements (i1) and (i2) (as in Table 1) in the questionnaire is to capture this essence.

Besides, enterprise-wide risk management initiatives can only be successfully implemented if everyone in the organization is clear about the type and nature of risk relevant to the enterprise. Thus, all pertinent information about the existing and potential risk faced by the enterprise must be effectively disseminated. Channel of communication must be open to facilitate top-down and bottom-up communication taking place to ensure all members of the firm understand their roles and responsibility with regard to the risk [1], [2]. The inclusion of statements (i3) and (i9) is to serve this end.

Statements (i4), (i8), (i10), and (i13) are included to capture the philosophy of ERM program. The essence and the very notion of ERM implementation are to integrate risk with business objectives and to align risk management initiatives with the overall corporate strategy in order to attain competitive advantages. This alignment and integration of risk must pervasively envelop all business units in the firm [3]-[5].

Statement (i14) relates to ERM providing rigor to enterprise to enhance its capability in identifying and selecting among alternative risk responses. The responses include risk avoidance, reduction, sharing and acceptance. The ability and efficiency of a firm to identify risk and subsequently respond to it are elements which are integral to an effective corporate risk management program [6].

In the enterprise's day-to-day operating environment, one of the many business objectives involves a compliance objective to the applicable laws and regulations. This objective is especially apparent in highly regulated industries such as finance, banking, gaming, and public utilities sectors. Compliance can also relate to meeting firms' internal corporate governance requirements. The cost incurred in such compliance initiatives can make up a significant chunk of the overall business operating cost. Hence, the inclusion of statements (i5) and (i6) in the questionnaire gauges how far ERM enables the management to track such compliance cost and the risk of non-compliance.

Statement (i7) relates to risk quantification. Before any specific response with regard to risk can be undertaken, enterprise needs to quantify them. Most of the quantification processes will involve the conversion of calculated risk into currency denomination. This is to provide a precise perspective to facilitate decision rule in the light of potential loss or damages in monetary terms before any response decision is made.

Statements (i11) and (i12) relate to performance measurement. The underpinning philosophy of implementing ERM program is to transform the entire organization to an enterprise that is internalized with "risk-aware" culture. To this end, it is imperative to identify key risk indicators (KRI) relevant to the firm's business and to tie those KRIs to staff members' key performance indicators (KPI). These KRIs and KPIs will enhance the firm's focus on balanced risk-reward trade-offs by effectively rewarding people for taking smarter risks [3], [7].

\section{B. Perceived ERM Benefit Measures}

The second construct in the theorized effective ERM implementation relationship model is perceived ERM benefit measures. This perceived ERM benefit measures can also be interpreted as the outcome derived from implementing ERM program. It can also be viewed as the motives for firms to engage in enterprise risk management program.

There are twenty statements presented to respondents for their agreement assessment in a 5-point Likert's scale format. The statements are as follows: (b1) enhances enterprise's ability to take appropriate risks in value creation, (b2) 
strengthens management's confidence in business operations, (b3) creates smooth governance procedures, (b4) improves monitoring of enterprise performance, (b5) enriches corporate reputation, (b6) improves clarity of organization-wide decision-making and chain of command, (b7) facilitates reporting to regulators, (b8) improves communicating to stakeholders / shareholders, (b9) enhances managers' ability to think entrepreneurially and innovatively, (b10) boosts enterprise's profitability, (b11) assists in meeting enterprise's strategic goals, (b12) reduces expected costs of financial distress, (b13) protects company's investments, (b14) reduces volatility of managers' bonuses and salaries, (b15) reduces informational gap (asymmetries) between management and shareholders, (b16) Managers are risk conscious , (b17) ERM implementation has a positive impact on enterprise's credit rating, (b18) ERM helps our enterprise to be respected within the industry, (b19) ERM can minimize agency problem/cost, (b20) Implementing ERM program will be rewarded by the equity market.

These statements are drawn from (i) conceptualization of strategic risk premium model [8]; (ii) Pricewaterhouse Cooper's 7th Annual Global CEO Survey on ERM; (iii) COSO framework of ERM [1]; and (iv) literature on the motives for corporate risk management such as those discussed in [9]. These literatures among others, touch on financial distress cost hypothesis, costly external financing hypothesis, informational asymmetries hypothesis, and corporate tax minimization hypothesis [10].

For instance, the strategic risk premium model posits that apart from macroeconomic risk, a firm's expected returns are also sensitive to tactical, strategic, and normative risks, hence affecting its risk premium. Tactical, strategic, and normative risks are classes of firm-specific risk defined by the strategic risk premium model [8]. Thus, it follows that the outcomes of managing these risks are to lower investors' expectation on the firm's risk premium. In this light, statements (b3), (b7), and (b8) relate to the governance aspect of the tactical risk whilst statements (b4), (b10), (b12), (b13), and (b14) relate to the earning-liquidity management of the tactical risk. Statements (b5), (b6), and (b9) relate to the firm-structure view of the strategic risk while statements (b1), (b2), and (b16) relate to the knowledge-based view of the strategic risk. Statements (b11) and (b15) reflect the overall management of strategic risk and tactical risk respectively whereas statement (b7) relates to the normative risk of the firm.

\section{Implementation Challenge}

The third construct in the theorized causal relationship model of an effective ERM implementation as depicted in Fig. 1 involves that of ERM Implementation Challenge. This construct is proxied by nine statements measured in 5-point Likert's scale presented to respondents for their agreement rating with regard to the challenges faced during ERM implementation process. This construct is presented as a factor to potentially affect ERM implementation intensity. The construct attempts to highlight the fact that various challenges faced by a firm during ERM implementation will affect its implementation intensity and hence, its outcomes or success, i.e. perceived ERM benefit measures. These implementation challenges can be attributed to such limitations and constraints as in the areas of organizational structure, financial and human resources, information technology infrastructure, and expertise.

ERM implementation should be seen as a program within a broader context of business process reengineering (BPR) and organizational change. Hence, the nine statements measuring ERM challenges construct are drawn from strategy, BPR, and change management literature such as those of [11], [12]. These nine statements are: (c1) people is an area posing big challenge, (c2) timeliness of information is a problem, (c3) lack of information needed, (c4) over-regulation in organization hinder ERM implementation, (c5) strong competition from other type of management techniques to be implemented, (c6) wide discrepancy between expectation and practices in ERM implementation, (c7) inadequate technology support (i.e. installation of information technology system for risk identification and assessment), (c8) organization structure deters ERM implementation, (c9) insufficient necessary level of investment for ERM implementation.

\section{EXAMINING ERM PRACTICE AMONG PLCS}

To examine the penetration of ERM practices among the Malaysian public listed companies (PLCs), this study analyzed the frequency distribution of mean scores for the summated scales of the various dimensions and areas of the ERM implementation intensity answered in the questionnaire. To provide a clearer perspective and better interpretation of the results of PLCs' ERM implementation intensity, this paper develops a descriptive semantic scale as shown in Table II to serve as a reference to the corresponding ranges of the summated scales' mean scores computed from the 5-point Likert's scale.

\begin{tabular}{cc} 
TABLE II: SEMANTIC SCALE FOR ERM IMPLEMENTATION INTENSITY \\
\hline \hline $\begin{array}{c}\text { Mean score } \\
\text { (on 5-point Likert's scale) }\end{array}$ & $\begin{array}{c}\text { Semantic scale } \\
\text { (ERM Implementation Intensity) }\end{array}$ \\
\hline $4.0-5.0$ & Excellent \\
$3.5-4.0$ & Good \\
$3.0-3.5$ & Satisfactory \\
$<3.0$ & Poor \\
\hline \hline
\end{tabular}

Results of the mean scores for each ERM implementation dimension, its overall average mean score, and their corresponding semantic scale interpretations are presented in Table III.

TABLE III: MEAN SCORE ANALYSIS RESULT OF ERM IMPLEMENTATION INTENSITY

\begin{tabular}{ccc}
\hline \hline ERM Dimension & Mean Score & Semantic Scale \\
\hline Structure & 3.89 & Good \\
Governance & 3.75 & Good \\
Process & 3.81 & Good \\
& & \\
\hline Overall average & 3.82 & Good \\
\hline \hline
\end{tabular}

Results in Table III indicate the overall average mean score gauging the PLCs' ERM implementation intensity is 3.82. This value falls within the semantic scale of 'good' as defined in Table II. As a result, it can be inferred that the 
overall ERM penetration level among the PLCs is rather encouraging.

The detailed results of the survey descriptive frequency distribution analysis for each area of the ERMimplementation intensity dimension are presented in the following sections and subsections:

\section{A. The Structure Dimension of ERM}

Table IV presents the mean scores for each item (statement) in the questionnaire that are measured in 5-point Likert's scale gauging the structure dimension of ERM implementation framework. There are four items measuring this dimension, i.e. i1, i2, i11, and i12. Two items covering an area each. As shown in Table IV, the mean scores range from 3.70 to 4.06 , all falling within the 'good' category of the semantic scale interpretation (refer to Table II).

TABLE IV: MEAN SCORE OF STRUCTURE DIMENSION IMPLEMENTATION PENETRATION

\begin{tabular}{|c|c|c|c|}
\hline Area & Item & Element & $\begin{array}{l}\text { Mean } \\
\text { Score }\end{array}$ \\
\hline \multirow[t]{2}{*}{$\begin{array}{c}\text { ERM } \\
\text { Definition }\end{array}$} & i1 & $\begin{array}{l}\text { Provides common understanding } \\
\text { of the objectives of each ERM } \\
\text { initiative }\end{array}$ & 3.83 \\
\hline & i2 & $\begin{array}{l}\text { Provides common terminology } \\
\text { and set of standards of risk } \\
\text { management }\end{array}$ & 4.06 \\
\hline \multirow{2}{*}{$\begin{array}{l}\text { Performance } \\
\text { measurement }\end{array}$} & i11 & $\begin{array}{l}\text { Identifies key risk indicators } \\
\text { (KRIs) }\end{array}$ & 3.98 \\
\hline & i12 & $\begin{array}{l}\text { Integrates risk with key } \\
\text { performance indicators (KPIs) }\end{array}$ & 3.70 \\
\hline
\end{tabular}

\section{B. The Governance Dimension of ERM}

Table $\mathrm{V}$ displays the mean scores for four items, i.e. i3, i9, i5, and i6, which measure the governance dimension of ERM implementation framework. Out of these four items, two items (i3 and i9) cover the area of information and roles whilst another two items (i5 and i6) cover the area of compliance. Results in Table V indicate that the average mean scores for the two areas in the governance dimension are 3.98 for information and roles and 3.52 for compliance respectively, the values of which are within the 'good' category of the semantic scale interpretation.

TABLE V: MEAN SCORE OF GOVERNANCE DIMENSION IMPLEMENTATION PENETRATION

\begin{tabular}{c|c|l|c|}
\hline \multicolumn{1}{c}{ Item } & \multicolumn{2}{c}{ Element } & $\begin{array}{c}\text { Mean } \\
\text { Score }\end{array}$ \\
\hline $\begin{array}{c}\text { Information } \\
\text { and roles }\end{array}$ & i3 & $\begin{array}{l}\text { Provides enterprise-wide } \\
\text { information about risk }\end{array}$ & 4.02 \\
\cline { 2 - 5 } & i9 & $\begin{array}{l}\text { Enables everyone to understand } \\
\text { his/her accountability }\end{array}$ & 3.93 \\
\hline \multirow{2}{*}{ Compliance } & i5 & Reduces risk of non-compliance & 3.78 \\
\cline { 2 - 5 } & i6 & $\begin{array}{l}\text { Enables tracking costs of } \\
\text { compliance }\end{array}$ & 3.26 \\
\hline
\end{tabular}

\section{The Process Dimension of ERM}

Table VI presents the mean scores for six items, i.e. i4, i8, i10, i13, i14, and i7. These six items measure the process dimension of ERM implementation framework. Out of these six items, four items (i4, i8, i10, and i13) cover the area of integration of business strategy and objectives whilst one item (i14) measures the area of risk identification and response and another item (i7) gauges risk quantification. Results in Table VI indicate that the average mean scores for all the three areas in this process dimension of ERM implementation framework are within the 3.5 to 4.0 range of implementation intensity, which corresponds to the 'good' category of the semantic scale interpretation.

TABLE VI: MEAN SCORE OF PROCESS DIMENSION IMPLEMENTATION PENETRATION

\begin{tabular}{|c|c|c|c|}
\hline Area & IItem & Element & $\begin{array}{l}\text { Mean } \\
\text { Score }\end{array}$ \\
\hline \multirow{4}{*}{$\begin{array}{l}\text { Integration of } \\
\text { business } \\
\text { strategy and } \\
\text { objectives }\end{array}$} & i4 & $\begin{array}{l}\text { Integrates risk with corporate } \\
\text { strategic planning }\end{array}$ & 3.90 \\
\hline & i8 & $\begin{array}{l}\text { Integrated across all functions and } \\
\text { business units }\end{array}$ & 3.80 \\
\hline & $\mathrm{i} 10$ & $\begin{array}{l}\text { ERM strategy is aligned with } \\
\text { corporate strategy }\end{array}$ & 3.93 \\
\hline & i13 & $\begin{array}{l}\text { Aligns ERM initiatives to business } \\
\text { objectives }\end{array}$ & 3.74 \\
\hline $\begin{array}{l}\text { Risk } \\
\text { identification } \\
\text { and response }\end{array}$ & i14 & $\begin{array}{l}\text { Provides the rigor to identify and } \\
\text { select risk responses (i.e. risk- } \\
\text { avoidance, reduction, sharing and } \\
\text { acceptance) }\end{array}$ & 3.77 \\
\hline $\begin{array}{c}\text { Risk } \\
\text { quantification }\end{array}$ & i7 & $\begin{array}{l}\text { Quantifies risk to the greatest } \\
\text { extent possible }\end{array}$ & 3.69 \\
\hline
\end{tabular}

\section{Discussion on the ERM Penetration by the PLCs}

The mean scores of all fourteen statements in the questionnaire measuring ERM implementation intensity (i.e. items i1, i2, i3, i4, i5, i6, i7, i8, i9, i10, i11, i12, i13, and i14) were computed. The average mean scores were examined for the depth of penetration of ERM practices among the respondents. Analysis of the mean scores along the three dimensions and the various areas of the ERM implementation framework was also performed.

Results of the analysis indicate that the intensity of ERM program implementation among the respondents is 'good', with the average mean score of 3.82 on the 5-point Likert's scale. Hence, it can be concluded that the penetration of ERM practices among Malaysian listed companies are relatively encouraging. This is so considering that Malaysia does not have specific laws governing corporate risk management like that of SOX in the United States and Japan. Obviously, it would seem to be in the best interest of shareholders of the PLCs if the results would have been in the category of "excellent". Nonetheless, by placing the findings in a proper perspective (vis-à-vis the regulatory requirement for ERM in Malaysia), it seems that the penetration of ERM practices among the PLCs are in the desirable state.

\section{FACTOR ANALYSIS}

\section{A. Reliability Analysis}

SPSS was used to perform reliability analysis to compute the Cronbach's alpha on the variables. The analysis was to test the degree of consistency of variables when measuring the indicators for ERM implementation intensity, 
implementation challenge, and perceived ERM benefit measures for the ERM practical framework. The indicators were denominated alphabetically and numerically in a systematic manner. For instance, indicators for the three constructs: implementation intensity, implementation challenge, perceived benefit measures were denoted i1, i2, i3, etc. (for implementation intensity); c1, c2, c3, etc. (for implementation challenge); and b1, b2, b3, etc. (for perceived benefit measures) respectively. The corresponding indicators for the three constructs are shown in section III (A), (B) and (C). A rule of thumb suggests that the acceptable Cronbach's alpha value should exceed 0.7 . The Cronbach's alpha value was 0.900 implying the questionnaire was measuring the ERM implementation intensity, implementation challenge, and perceived ERM benefit measures in a useful manner. Hence, all variables were retained. The calculation of reliability analysis was based on the recommended default settings of the SPSS Application Guide [13].

\section{B. Exploratory Factor Analysis}

TABLE VII: FACTORS EXTRACTED USING EXPLORATORY FACTOR ANALYSIS

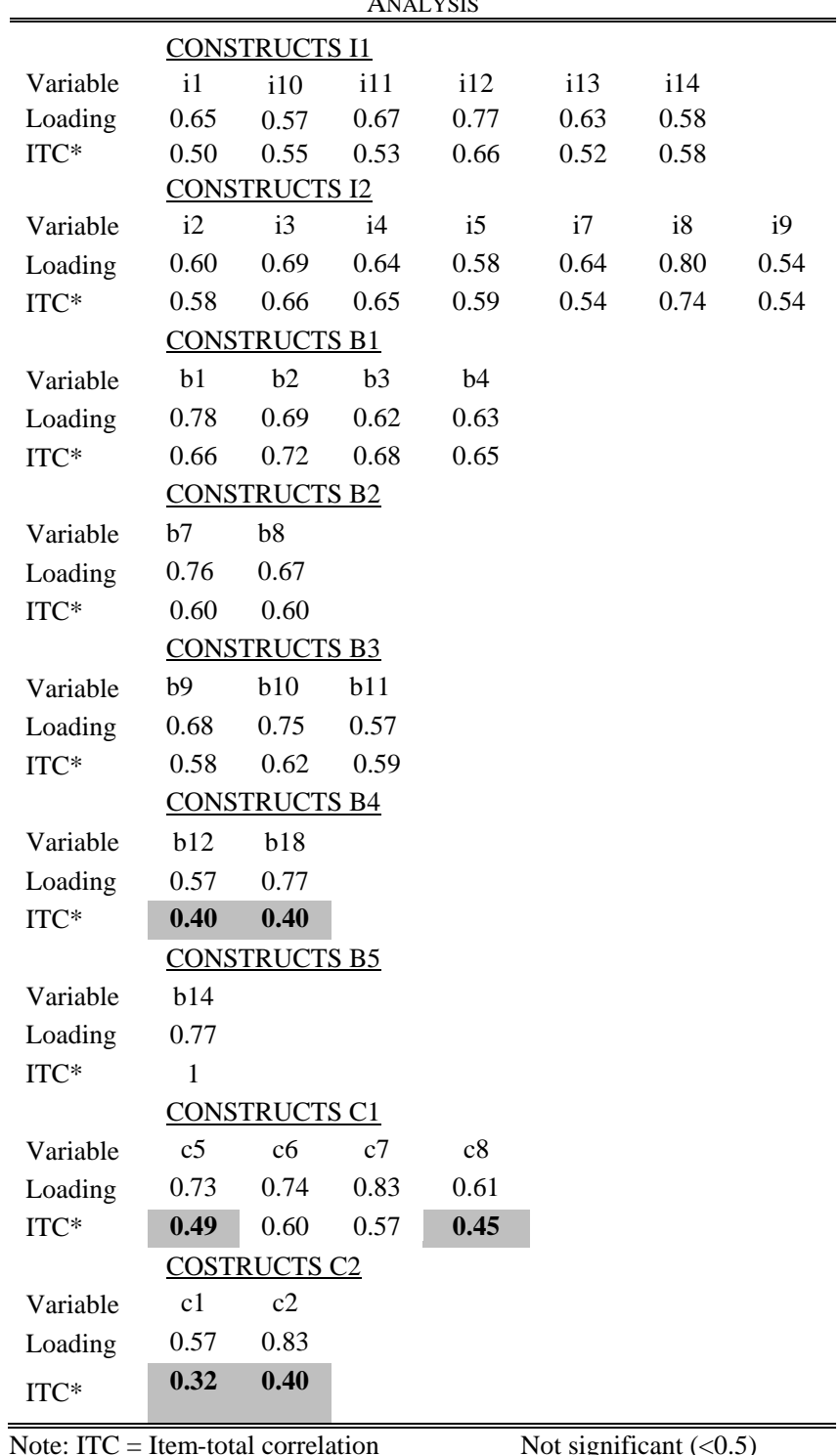

Exploratory factor analysis (EFA) was performed using SPSS on the dataset collected through survey questionnaire from the PLCs. The objective is to describe variability among observed, correlated variables in terms of a potentially lower number of unobserved (latent) variables called factors. The EFA's statistical computation includes only variance that is common among the variables whereby the researcher makes the assumption that an underlying causal model exists. Only factor loadings with values above 0.3 were displayed whilst only factor loadings above 0.5 were considered significant. The EFA results indicated that variables c3, b5, b6, b13, b16 were insignificant and they were dropped for further analysis. EFA provided insight to the researcher in regard to how many factors could be extracted for each construct based on the designed survey instrument. Factors extraction method followed latent root criterion in which only factors with eigenvalues greater than 1 were considered significant.

The results of the EFA showed nine factors were extracted from all the variables. These nine factors together accounted for almost 70 percent of the data variance. Examination of the Kaiser-Meyer-Olkin (KMO) measure of sampling adequacy showed a coefficient of 0.821 , which was above the acceptable level of 0.7 . The Bartlett's test of sphericity, which is a statistical test for the overall significance of all correlations within a correlation matrix, was also statistically significant at $\alpha=0.01$ level. Out of the nine factors, two factors were extracted for the ERM implementation intensity construct (denoted I1 and I2), two factors for the implementation challenge construct (denoted $\mathrm{C} 1$ and $\mathrm{C} 2$ ), and five factors were extracted for the perceived benefit measures construct (denoted B1, B2, B3, B4, and B5). The nine factors extracted and their respective indicators are shown in Table VII [13].

\section{Reliability of Factors' Scales}

After factors were extracted from the exploratory factor analysis, reliability test was conducted again on the respective factor scale. Statistically, it involved the item-total correlation for variables within a scale or factor. Table VIII presents the results of the item-total correlation. The cut-off point of an acceptable item-total correlation is 0.5 or above. As Table VIII indicates, variables b12, b18, and c8, failed to attain item-total correlation above the 0.5 threshold. Hence, these variables were omitted for further analysis. Note that variable c5 initially did not make the cut for the 0.5 threshold for factor $\mathrm{C} 1$, subsequent scale reliability test after deleting c8 however, revealed that c5's Cronbach's alpha in factor C1 was 0.504 . As such we retained $\mathrm{c} 5$ in factor $\mathrm{C} 1$ for further analysis.

Table VIII shows the Cronbach's alpha statistic for the factor scales of the retained variables. The Cronbach's alpha value for each factor scale is above the recommended value of 0.7 , indicating the scales' internal consistency [13].

TABLE VIII: CRONBACH'S ALPHA STATISTIC FOR FACTOR SCALE

\begin{tabular}{cccc}
\hline \hline Factor & Indicators & No of Items & $\begin{array}{c}\text { Scale's } \\
\text { Cronbach's } \alpha\end{array}$ \\
\hline I1 & i1, i10, i11, i12, i13, i14 & 6 & 0.804 \\
I2 & i2, i3, i4, i5, i7, i8, i9 & 7 & 0.855 \\
B1 & b1, b2, b3, b4 & 4 & 0.844 \\
B2 & b7, b8 & 2 & 0.748 \\
B3 & b9, b10, b11 & 3 & 0.764 \\
C1 & c6, c7, c8 & 3 & 0.718 \\
\hline \hline
\end{tabular}


After two rounds of data reduction process, i.e. through exploratory factor analysis' factor loadings analysis and item-total correlation's coefficient analysis, the study had eliminated a total of eleven variables. This means only twenty five variables were retained for further analysis.

\section{Naming of the Factors}

With the derivation of the above six-factor solution (i.e. two for ERM implementation intensity construct - I1, I2; three for perceived benefit measures construct - B1, B2, B3; and one for implementation challenge construct - $\mathrm{C} 1$, the researcher could attempt to name these latent variables in order to provide meaningful description to each of them. Naming the factors was not done arbitrarily. The process involved "substantive interpretation of the pattern of factor loadings for the variable" [13]. It also helps if the researcher possesses prior knowledge of what to expect after extensive literature review in order to give a bigger picture of what those factors represent. The researcher named the factors as shown in Table IX.

TABLE IX: NAMING OF THE FACTORS

\begin{tabular}{cc}
\hline \hline Factor & Name (Description) \\
\hline I1 & performance \& target setting \\
I2 & business function \& process integration \\
B1 & risk taking capability \& confidence building \\
B2 & effective stakeholders communication \\
B3 & enterprise \& managerial excellence \\
C1 & implementation challenges \\
\hline \hline
\end{tabular}

\section{CONCLUSION}

This paper presents an empirical examination into ERM implementation framework through exploratory factor analysis on its dimensions, areas, and elements. Data was collected from public listed companies in Malaysia for the purpose and also to investigate the penetration level of ERM practices among the sampled public listed companies. The findings have provided insights to business enterprises, shareholders as well as regulators on what an effective ERM implementation framework entails in terms of its dimensions, areas and elements and how these elements correlate with each other.

The outcomes from the exploratory factor analysis which highlight the constructs and the corresponding factors for ERM implementation intensity, challenges, and perceived benefit measures can be used for a further study to develop a structural equation modeling (confirmatory factor analysis) investigating the causal relationship among the endogenous and exogenous constructs/factors which can be further theorized in tandem with the findings presented above [9], [14].

\section{REFERENCES}

[1] M. S. Beasley, B. C. Branson, and B. V. Hancock, "Current state of enterprise risk oversight and market perceptions of COSO's ERM framework," COSO's 2010 Report on ERM, 2010.

[2] C. Chapman, "Bringing ERM into focus," The Internal Auditor, vol. 60, no. 3, pp. 30, 2003.

[3] M. A. Bailey, L. Bloom, and E. T. Hida, "Assessing the Value of Enterprise Risk Management,” Deloitte Development LLC, 2004.

[4] J. Lam, Enterprise Risk Management: From Incentive to Controls, New Jersey: John Wiley, 2003.

[5] D. R. Hermanson, "The implications of COSO's Proposed ERM framework," Internal Auditing, vol. 18, no. 6, pp. 41, 2003.

[6] G. J. Bierc, "Risk management infrastructure can boost corporate performance," Financial Executive, vol. 19, no. 3, pp. 59-61, 2003.

[7] S. Rucker. (July 2008). Gauging success with key performance indicators. Risk Management [Online]. Available: http://findarticles.com/p/articles/mi_qa5332/is_200202/ai_n2130819

[8] S. Chatterjee, M. H. Lubatkin, and W. S. Schulze, "Toward a strategic theory of risk premium: moving beyond CAPM," The Academy of Management Review, vol. 24, no. 3, pp. 556-567, 1999.

[9] F. W. Lai and N. A. Azizan, "Critical review of literature on enterprise risk management and the cost of capital: The value creation perspective," African Journal of Business Management, vol. 6, no. 9, pp. 3126-3133, March 2012.

[10] F. W. Lai and M. F. Samad, "Enterprise risk management framework and the empirical determinants of its implementation," 2010 International Conference on Business and Economics Research, Kuala Lumpur, vol. 1, pp. 340-344, 2011.

[11] N. Graf, "Uncovering the risk conundrum: a strategic perspective," EHL-FORUM, no. 4, June 2004.

[12] K. W. Khong and S. Richardson, "Business process re-engineering (BPR) in Malaysian banks and finance companies," Managing Service Quality, vol. 13, no. 1, pp. 54-71, 2003.

[13] J. F. Hair, W. C. Black, B. J. Babin, and R. E. Anderson, Multivariate Data Analysis, 7th ed. New Jersey: Prentice Hall, 2010.

[14] F. W. Lai, M. F. A. Samad, and N. A. Azizan, "Multifactor model of risk and return through enterprise risk management framework," International Proceedings of Economic Development and Research, vol. 12, pp. 555-559, August 2011.

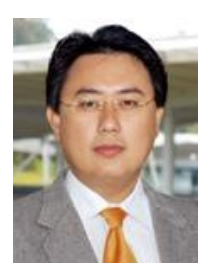

Fong-Woon Lai is a senior lecturer at Universiti Teknologi PETRONAS in Malaysia. He holds a Bachelor of Science degree in Business Administration (Finance) and a Master of Business Administration (Finance) from the University of Nebraska-Lincoln, USA. He obtained his Ph.D (in enterprise risk management) from the University of Malaya, the oldest university in Malaysia. He has been teaching in higher learning institutions since 1998. Prior to joining education line, Dr. Lai has worked in two stock broking companies in Malaysia. He held an Investment Advisor's Representative License issued by the Malaysian Securities Commission in 1997. He was also an external writer for licensing examinations conducted by an industry authority in the country. Dr. Lai has also published in indexed journals and presented in local and international conferences his research papers in the areas of corporate finance and risk management, business process re-engineering and higher education research. Dr. Lai's past and present professional body memberships include the Australasian Institute of Banking and Finance, Malaysian Institute of Management, Professional Risk Managers International Association and Malaysian Association of Risk and Insurance Management. 